\title{
Carbon Emission Impact for Energy Strategy in Which All Non-CCS Coal Power Plants Are Replaced by NPPs
}

\author{
Vladimir Knapp ${ }^{1}$, Mario Matijević ${ }^{1}$, Dubravko Pevec ${ }^{1}$ and Dinka Lale ${ }^{2}$ \\ 1. Faculty of Electrical Engineering and Computing, University of Zagreb, Unska 3, Zagreb 10000, Croatia \\ 2. Department of Electrical Engineering and Computing, University of Dubrovnik, Ćira Carića 4, Dubrovnik 20000, Croatia
}

Received: July 29, 2016 / Accepted: August 22, 2016 / Published: January 31, 2017.

\begin{abstract}
A threat of global warming should convince the public to accept a nuclear fission energy contribution to climate change mitigation, at least for the climate critical years up to 2065. The nuclear fission energy is available now, with proven reactors, such as advanced LWR (light water reactors). Nuclear strategy in this paper outlines a proposal to replace all coal power plants (without carbon and capture storage system) with nuclear power plants in the period 2025-2065. Assuming once through advanced LWR technology, one would need nuclear capacity of $1,600 \mathrm{GW}$ to replace coal power plants in that period. Corresponding reduction of emission would amount to $11.8 \mathrm{Gt}$ of $\mathrm{CO}_{2}$. This energy strategy would reduce carbon emission by approximately $22 \%$ in the year 2065 and would be covered by projected uranium resources. An estimation of replacement costs showed that future carbon tax has a considerable potential to offset higher costs of nuclear replacement power.
\end{abstract}

Key words: Global warming, uranium resources, carbon emission, energy strategy.

\section{Introduction}

Global warming is the most serious nature response to human mismanagement of natural environment. After more than 40 years of research great majority of climate scientists agree that climate change is caused by human action and that human action could also control it, but the time available is very limited and effectively excludes many mitigation measures.

As in no time in history, nature, with its own rules and laws, forces us to look into the future not in decades but in centuries. Human action is putting carbon dioxide into atmosphere where it resides effectively for hundreds of years. We are forced to look ahead on the same time scale but we have much shorter time to act as we almost used up the quota of emission of carbon before disaster would be unavoidable. We have to change our ways of relaying

Corresponding author: Dubravko Pevec, Ph.D., professor, research fields: nuclear engineering, energy engineering. on fossil fuel dramatically in next few decades. Last report by IPCC AR 5 WG 3 [1] states that between 2000 and 2010 GHG (greenhouse gas) emissions grew at $2.2 \%$ a year, almost twice as fast as in previous 30 years. At that rate, report says, the world will pass the $2{ }^{\circ} \mathrm{C}$ temperature rise by 2030. Last GHG emission figure for the period 2000-2010 is (49 \pm 4.5$) \mathrm{Gt} \mathrm{CO}_{2}$ eq/year. Important quantification on the available time is given in the paper by Meinshausen et al. [2]. To compare the data we note that in the period 1970-2010 a share of fossil fuel combustion in total GHG emission was $78 \%$. We give some most important results here. In order to keep global temperature rise till the end of century below $2{ }^{\circ} \mathrm{C}$, with the probability not exceeding this limit of $25 \%(50 \%)$, the world would have to limit cumulative emission of $\mathrm{CO}_{2}$ in the interval 2000-2050 to $1,000 \mathrm{Gt}(1,440 \mathrm{Gt})$. As the emission of $\mathrm{CO}_{2}$ during the interval 2000-2006 amounted to $234 \mathrm{Gt}$ of $\mathrm{CO}_{2}$ [2], we should appreciate the magnitude of the problem. Assuming continuation of average annual emission of $36.3 \mathrm{Gt}$ from fossil 
fuels, forestry and land use we would exhaust emission budget by 2027 respectively by 2039 (for $50 \%$ probability not exceeding $2{ }^{\circ} \mathrm{C}$ ). Very similar results are given in a more recent calculation by Friedlingstein from Exeter University [3]. On this time scale it is very difficult to see the solution without aggressive counter measures. Most aggressive plans to develop alternative energy sources are inadequate for the next 30 years. In a recent study by Ross Koningstein and David Fork, scientists from Google, conclude, with regrets, that even the best scenario for development of renewable sources will not be in time [4] to cover the needs without share of other non-fossil energy sources. Large scale CCS (carbon capture and storage) is at least 30 to 50 years away, if at all, nuclear fusion further still. On the other hand two paths seem to have a chance of timely emission reduction; serious energy saving in industry, transport and heating and a second additional way is the rapid deployment of now available nuclear fission energy. Large scale nuclear contribution needed in short time of few decades can only be based on existing proven reactors. Operating reactors, some 430, are predominantly light water cooled and moderated (LWR). Some have over 40 years of operation. Our first task was to establish if by use of proven technology of LWR reactors nuclear fission with available uranium resources nuclear energy can give an essential contribution to the carbon emission reduction required to reach emissions compatible with the $2{ }^{\circ} \mathrm{C}$ limit. Following the condition of applying developed and proven technology, we focused on the nuclear fission energy produced in LWR, a technology that has decades of experience in commercial energy production. Request to consider only once-through fuel cycle without reprocessing of spent fuel was a result of both political and techno-economical considerations. With typical efficiency of such fuel cycle in LWR reactors we set ourselves the task of evaluation of maximum nuclear capacity under these fuel cycle limitations and the limitation by available uranium resources. To qualify as an essential nuclear contribution, we assume that at least one third of the reduction requested by IPCC should be attainable. Other essential reduction would expectedly be covered by energy saving and renewable sources, mainly wind and solar. Quantization of required emission reduction was based on IEA WEO projections of future emissions and on their WEO 450 energy strategy that would limit $\mathrm{CO}_{2}$ concentration under $450 \mathrm{ppm}$ [5]. As is evident from the cited IPCC report [1] and by studies of Meinshausen et al. [2] emission reduction is not sufficient by itself. It must be reached within limited time window, as there is a limit on integral $\mathrm{CO}_{2}$ emission resulting from long residence of $\mathrm{CO}_{2}$ in atmosphere. Consequently, our considerations were done under important physical constraint that essential reduction of emission must be achieved in only few decades.

\section{Comments on Some Mitigation Technologies}

In our judgment such sources as nuclear fusion and fossil fuels with CCS are eliminated on that time scale as a large scale producer of carbon free energy, irrespective of their future prospects. In spite of expected break-even in a laser fusion, technical problems with suitable laser do not give ground for more optimism. Magnetic fusion with ITER project costing tens of billions dollars may eventually lead to energy producing device, surely an excellent scientific achievement crowning decades of hard science, but fusion energy power plant, necessarily of large size, with superconductor magnets, plasma heating devices and fuel breeding will be so complex that very few utilities would risk building, running, and maintaining them. It may well be another but more costly Concorde. More applicable new fusion concepts which may emerge will have to pass through decades of developing and testing. Whilst work on CCS is in progress on the experimental level of million tons of $\mathrm{CO}_{2}$ a year, a thousand times larger level of billions of 
tons per year is needed for essential emission reduction. Biello [6] gives information on largest American CCS projects Boundary Dam and Kemper plants. The cost of the plants is reported to be 11,000 and 10,000 dollars per $\mathrm{kW}$ of generating capacity. Large Kemper facility costing 6.3 billions dollars is expected to remove $65 \%$ of $\mathrm{CO}_{2}$ that would be otherwise emitted. Amongst many project cancelled the surviving ones have used $\mathrm{CO}_{2}$ for oil well stimulation, but in these utilisations the main aim is not permanent storage. Only 15 projects are operating worldwide while 33 have been scraped according to Biello. No reason to expect a solution by CCS for many decades, if at all. It is in spirit of science that ideas which could lead to solution of the problem should be explored, but with magnetic Tokamak fusion and CCS it is clear that there is not going to be usable solution on the required large scale. The sooner this is accepted, the sooner the inertia of big fusion and CCS projects can be broken and we could concentrate on the more promising solutions. Thus we must in the climate critical period of few decades rely on nuclear energy from LWR reactors operating with safe nuclear cycle, as well as on the renewable sources in various stages of development and deployment and on the energy saving and more efficient use. Nuclear energy covering the base load would be a natural part of energy system with large production of intermittent energy sources. Knowing the uranium sources and the fuel cycle limitations our task was to see whether nuclear power could be technically and industrially developed in capacity to cover an essential part of the required emission reduction in the time period relevant for effective climate change mitigation.

\section{Selection of Fuel Sustainable Proven Nuclear Technology up to 2065}

In our preceding research [7] we have concentrated on the question whether nuclear fission energy subject to fuel cycle and resources limitation can give timely and essential contribution to carbon dioxide emission reduction. Our estimates of possible nuclear contribution can serve as defining targets for non-nuclear contributions. Considerations of possible nuclear fission contribution were made under several constraints dictated by technical, climate and political considerations. Time window for carbon emission reduction was determined by the nature of the climate problem and was decisive in selection of acceptable and available nuclear technology. Aware of the urgency of carbon emission reduction, but also with understanding that a drastic change of world energy production will take decades, we selected a time window for a nuclear build-up between the years 2025 and 2065. Initial year was chosen as to allow industrial and other preparation for the large scale nuclear power plants constructions; upper time limit is the year when large enough carbon emission reduction should be achieved if the integral emission limit is not to be infringed. Whilst shorter build-up period may be more desirable from the climate control point of view, we decided for the 40 years long nuclear build-up respecting the technical and economic problems of a massive construction program. Future alarming climate changes may yet force reconsiderations. Selected time window restricts the choices of energy technologies. As in selected period an essential contribution cannot be expected to come from nuclear fusion and CCS, the investigation was reduced to the question whether acceptable nuclear fission technology can, in that specified period, give essential contribution to carbon emission reduction. Criteria for acceptable technology were technical safety, proven in operational records and experience, and proliferation safety. First condition led to the selection of light water technology, and the second one to the selection of once through fuel cycle without fuel reprocessing and plutonium use. The selection of fuel cycle without reprocessing was determined with intention to give more time to introduce effective international institutions and controls in transport and use of 
plutonium. As uranium use in thermal reactors utilizes dominantly energy of $\mathrm{U}^{235}$; the appropriate question about nuclear contribution was whether uranium resources are large enough for an essential nuclear share by 2065, when expected energy needs will be considerably higher than present one. In our preceding research we assumed nuclear resources as given in so called Red Book [8]. To see if a large enough nuclear contribution can be reached by 2065, linear nuclear build-up in the period 2025-2065 was determined under condition that all uranium resources as estimated in 2008 amounting to $17.1 \mathrm{Mt}$ be consumed by 2065 . Only a part of these estimated resources have at present time the status of confirmed reserves but in future five decades estimates will grow with observed rates to considerably larger values. Our estimates in Ref. [9] are providing the support for this prediction. Supporting argument for the selection of open nuclear fuel cycle follows from consideration that plutonium produced in LWR till 2065 would be more valuable to preserve options considering fission energy production after 2065. Recycling of plutonium to LWR besides being of disputed economy, would postpone introduction of breeder reactors and thus would be counterproductive to any strategy of using fission energy after 2065. The upper limit to nuclear power build up under constraints given above was estimated to reach $3,330 \mathrm{GW}$ by 2065 with annual growths of $71.8 \mathrm{GW}$. The resulting maximum upper limit of nuclear power showed that nuclear energy would by 2065 cover more than one third of the emission reduction required to come down from "Business as usual" strategy to WEO 450 strategy limiting global temperature increase to $2{ }^{\circ} \mathrm{C}$ as specified in Ref. [5]. By 2065 proposed strategy would reach a very significant share of $39.6 \%$ of the required total $\mathrm{CO}_{2}$ emission reduction, respectively, $25.2 \mathrm{Gt}$ of $\mathrm{CO}_{2}$. This encouraging result led us to investigate if by less demanding nuclear strategy it would still be possible to obtain substantial reduction of carbon emission.

\section{Replacement All Non-CCS Coal Power Plants with Nuclear Power Plants in Years 2025-2065}

We present here updated proposal of nuclear strategy to replace all CPP (coal power plants), except those equipped with CCS systems, with advanced LWR NPP (nuclear power plants) in the period 2025-2065. This proposed nuclear strategy should be within industrial capabilities of future decades and would be by 2065 covered by uranium resources. Proposal is gaining relevance with reduced perspective of contribution of nuclear fusion and CCS technology in the period 2025-2065 essential for climate change mitigation.

The proposed strategy starts with generating nuclear power of $384 \mathrm{GW}$ in year 2016. We assumed linear increase in nuclear power to the value of $500 \mathrm{GW}$ in year 2025. This value is estimated from WNA (World Nuclear Association) and IEA (International Energy Agency) reports $[10,11]$. New data on coal power and new relevant climate data are obtained from IEA WEO 2015 publication [12]. Several energy scenarios are defined and analyzed in this publication. We refer to current policy scenario (based on business as usual practice) and WEO 450 scenario (limits $\mathrm{CO}_{2}$ concentration below $450 \mathrm{ppm}$ ). Our proposed strategy is defined by replacement of all CPPs with NPPs, except CPPs equipped with CCS installations, after the expiration of their working life in the period 2025-2065. According to the WEO2015 current policy scenario, electricity production from CPP in the 2025 would amount to $12,304 \mathrm{TWh}$ (extrapolation between 2020 and 2040 figures from Current Policies scenario). We take the CPP electricity production level predicted for 2025 in Current Policies as constant through the years from 2025-2065 expecting the restrained development of coal industry under the impact of climate mitigation measures and carbon emission taxation. To produce the same amount of electricity in NPPs the required installed power would be 1,600 $\mathrm{GW}$ assuming the capacity factor of nuclear power 
plants to be 0.88 . We assume an increase in NPP's capacity factor from 0.88 in 2025 to about 0.90 by 2065. The corresponding reduction of the required nuclear replacement power would probably be offset by the expected parallel increase in CPP efficiency, increasing the power to be replaced. Any precise predictions are impossible at present, and unnecessary in the long term strategic trends, so we determine the required total nuclear replacement power, assuming energy capacity factors to be constant in the 2025-2065 period for both nuclear and coal power plants. Consequently, assuming a linear nuclear build-up strategy, average annual construction of 40 GW would be required throughout the 2025-2065 period. The total installed nuclear power by the year 2065 would amount to $500+1600=2100 \mathrm{GW}$ assuming that the nuclear power plants in operation in 2025 , with predicted power of $500 \mathrm{GW}$, will operate until 2065, or else be replaced if they have to retire. NPPs constructed in the period 2025-2065 will continue operation after 2065 until the end of their working lives. The generating nuclear capacities after year 2065 depend on duration of NPP working life. We assumed working lives of 40 years and 60 years. The NPPs that are in operation in year 2065 will be all retired by the year 2105 if their working life is 40 years. Therefore, the generating nuclear capacity will linearly decrease from $2,100 \mathrm{GW}$ to $0 \mathrm{GW}$ in the period 2065-2105. For working life of 60 years the NPPs that are in operation in year 2065 could continue their operation on the power level of $2,100 \mathrm{GW}$ to the year 2085 and have to be all retired by the year 2125. Consequently, for this case the generating nuclear capacity will linearly decrease from $2,100 \mathrm{GW}$ to $0 \mathrm{GW}$ in the period 2085-2125. The nuclear generating capacity for working life of 60 years and working life of 40 years for the period 2015 to 2125 is given in Fig. 1.

Uranium requirements and plutonium production for proposed strategy are calculated by using average uranium requirements factors and average plutonium production factors per unit of produced energy for advanced LWR NPPs. The nuclear capacity, annual uranium requirements, cumulative uranium requirements, annual plutonium production and cumulative plutonium production to the year 2105 for working life of 40 years are given in Table 1. The nuclear capacity, annual uranium requirements, cumulative uranium requirements, annual plutonium production and cumulative plutonium production to the year 2125 for

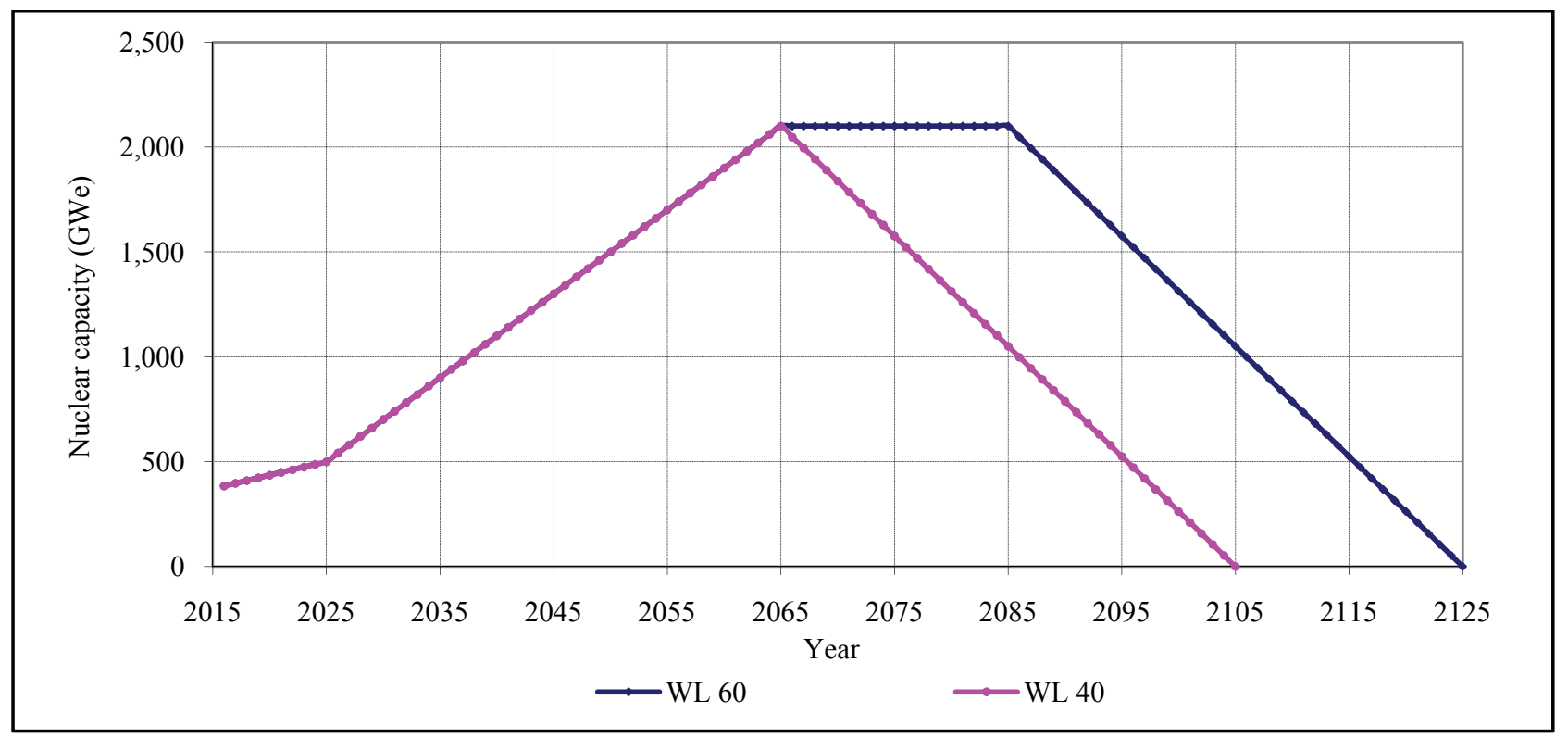

Fig. 1 The nuclear generating capacity for working life of 60 years (WL 60) and working life of 40 years (WL 40 ) for the period 2015-2125. 
Table 1 The nuclear capacity, annual uranium requirements, cumulative uranium requirements, annual plutonium production and cumulative plutonium production to the year 2105 for working life of 40 years.

\begin{tabular}{llllll}
\hline Year & $\begin{array}{l}\text { Nuclear capacity } \\
(\mathrm{GWe})\end{array}$ & $\begin{array}{l}\text { Annual uranium } \\
\text { requirements }(\mathrm{ktU})\end{array}$ & $\begin{array}{l}\text { Cumulative uranium } \\
\text { requirements } \\
(\mathrm{MtU})\end{array}$ & $\begin{array}{l}\text { Annual plutonium } \\
\text { production } \\
(\mathrm{tPu})\end{array}$ & $\begin{array}{l}\text { Cumulative plutonium } \\
\text { production } \\
\text { (Pu) }\end{array}$ \\
\hline 2016 & 384.00 & 59.20 & 0.06 & 59.20 & 59.20 \\
2020 & 435.56 & 67.15 & 0.32 & 67.15 & 315.89 \\
2025 & 500.00 & 77.09 & 0.68 & 77.09 & 681.46 \\
2030 & 700.00 & 108.23 & 1.16 & 108.23 & $1,160.25$ \\
2035 & 900.00 & 139.55 & 1.80 & 139.55 & $1,795.28$ \\
2040 & $1,100.00$ & 171.04 & 2.59 & 171.04 & $2,587.42$ \\
2045 & $1,300.00$ & 202.71 & 3.54 & 202.71 & $3,537.55$ \\
2050 & $1,500.00$ & 234.55 & 4.65 & 234.55 & $4,646.54$ \\
2055 & $1,700.00$ & 266.57 & 5.92 & 266.57 & $5,915.27$ \\
2060 & $1,900.00$ & 298.76 & 7.34 & 298.76 & $7,344.61$ \\
2065 & $2,100.00$ & 331.13 & 8.94 & 331.13 & $8,935.45$ \\
2070 & $1,837.50$ & 289.74 & 10.47 & 289.74 & $10,466.91$ \\
2075 & $1,575.00$ & 248.35 & 11.79 & 248.35 & $11,791.42$ \\
2080 & $1,312.50$ & 206.96 & 12.91 & 206.95 & $12,908.98$ \\
2085 & $1,050.00$ & 165.56 & 13.82 & 165.56 & $13,819.58$ \\
2090 & 787.50 & 124.17 & 14.52 & 124.17 & $14,523.23$ \\
2095 & 525.00 & 82.78 & 15.02 & 82.78 & $15,019.92$ \\
2100 & 262.50 & 41.39 & 15.31 & 41.39 & $15,309.66$ \\
2105 & 0.00 & 0.00 & 15.39 & 0.00 & $15,392.44$ \\
\hline & & & & & \\
\hline
\end{tabular}

working life of 60 years are given in Table 2. The cumulative uranium requirements for the proposed strategy to the year 2065 amount $8.94 \mathrm{Mt}$ of uranium what is within today's uranium resources. The cumulative plutonium production for the proposed strategy to the year 2065 amounts 8,935 $\mathrm{t}$ of plutonium.

To evaluate the mitigation effect of CPPs replacement by NPPs we estimated the reduction of $\mathrm{CO}_{2}$ emisson due to the proposed replacement. We use the coal appropriate figure for $\mathrm{CO}_{2}$ emission per unit electricity of $0.960 \mathrm{~kg} / \mathrm{kWh}$ for this estimate. Taking into account the annual production of 12,304 TWh of CPP and the fact that in the year 2065 all CPPs will be replaced by NPPs, the resulting $\mathrm{CO}_{2}$ emission saving in the year 2065 will reach $11.8 \mathrm{Gt}$. To assess the relative impact of these figures of emission saving, we compare them to 2065 extrapolations of $\mathrm{CO}_{2}$ emissions by current policies and WEO 450 scenarios data in WEO 2015.

Annual carbon dioxide emission reduction of 11.8 Gt, can be expressed as a fraction of carbon emission extrapolated to the end CPP replacement period. Extrapolated $\mathrm{CO}_{2}$ emissions in the year 2065 would be, with an error of some 5\%,54 Gt for current policy scenario. As a fraction of this figure, emission saving by replacing CPPs would be $21.9 \%$ in the year 2065 . This would be a significant contribution to the reduction of carbon emission, achieved without reprocessing nuclear fuel, and with uranium consumption well within the qualified 2008 and 2012 estimates. The other possibility is to compare annual carbon dioxide emission reduction of $11.8 \mathrm{Gt}$ in the year 2065 with the extrapolated total reduction of $45 \mathrm{Gt} \mathrm{CO}_{2}$ required to bring in the year 2065 the WEO current policy energy strategy down to the WEO 450 energy strategy limiting the global temperature increase to $2{ }^{\circ} \mathrm{C}$. As a fraction of this figure, emission saving by replacing CPPs would be $26.22 \%$ in the year 2065. $\mathrm{CO}_{2}$ emissions for WEO current policy energy strategy, WEO 450 energy strategy, and for proposed energy strategy in $\mathrm{GtCO}_{2}$ for the period 2013-2065 are given in Fig. 2. The upper curve are the $\mathrm{CO}_{2}$ emissions by the current practice strategy as defined in WEO 2015 
Table 2 The nuclear capacity, annual uranium requirements, cumulative uranium requirements, annual plutonium production and cumulative plutonium production for the Scenario 2 to the year 2125 (60 years working period).

\begin{tabular}{|c|c|c|c|c|c|}
\hline Year & $\begin{array}{l}\text { Nuclear capacity } \\
(\mathrm{GWe})\end{array}$ & $\begin{array}{l}\text { Annual uranium } \\
\text { requirements }(\mathrm{ktU})\end{array}$ & $\begin{array}{l}\text { Cumulative uranium } \\
\text { requirements } \\
(\mathrm{MtU})\end{array}$ & $\begin{array}{l}\text { Annual plutonium } \\
\text { production } \\
(\mathrm{tPu})\end{array}$ & $\begin{array}{l}\text { Cumulative plutonium } \\
\text { production } \\
(\mathrm{tPu})\end{array}$ \\
\hline 2016 & 384.00 & 59.20 & 0.06 & 59.20 & 59.20 \\
\hline 2020 & 435.56 & 67.15 & 0.32 & 67.15 & 315.89 \\
\hline 2025 & 500.00 & 77.09 & 0.68 & 77.09 & 681.46 \\
\hline 2030 & 700.00 & 108.23 & 1.16 & 108.23 & $1,160.25$ \\
\hline 2035 & 900.00 & 139.55 & 1.80 & 139.55 & $1,795.28$ \\
\hline 2040 & $1,100.00$ & 171.04 & 2.59 & 171.04 & $2,587.42$ \\
\hline 2045 & $1,300.00$ & 202.71 & 3.54 & 202.71 & $3,537.55$ \\
\hline 2050 & $1,500.00$ & 234.55 & 4.65 & 234.55 & $4,646.54$ \\
\hline 2055 & $1,700.00$ & 266.57 & 5.92 & 266.57 & $5,915.27$ \\
\hline 2060 & $1,900.00$ & 298.76 & 7.34 & 298.76 & $7,344.61$ \\
\hline 2065 & $2,100.00$ & 331.13 & 8.94 & 331.13 & $8,935.45$ \\
\hline 2070 & $2,100.00$ & 331.13 & 10.59 & 331.13 & $10,591.09$ \\
\hline 2075 & $2,100.00$ & 331.13 & 12.25 & 331.13 & $12,246.73$ \\
\hline 2080 & $2,100.00$ & 331.13 & 13.90 & 331.13 & $13,902.37$ \\
\hline 2085 & $2,100.00$ & 331.13 & 15.56 & 331.13 & $15,558.01$ \\
\hline 2090 & $1,837.50$ & 289.74 & 17.09 & 289.74 & $17,089.47$ \\
\hline 2095 & $1,575.00$ & 248.35 & 18.41 & 248.35 & $18,413.98$ \\
\hline 2100 & $1,312.50$ & 206.96 & 19.53 & 206.95 & $19,531.54$ \\
\hline 2105 & $1,050.00$ & 165.56 & 20.44 & 165.56 & $20,442.14$ \\
\hline 2110 & 787.50 & 124.17 & 21.15 & 124.17 & $21,145.79$ \\
\hline 2115 & 525.00 & 82.78 & 21.64 & 82.78 & $21,642.48$ \\
\hline 2120 & 262.50 & 41.39 & 21.93 & 41.39 & $21,932.22$ \\
\hline 2125 & 0.00 & 0.00 & 22.02 & 0.00 & $22,015.00$ \\
\hline
\end{tabular}

and lower curve are the $\mathrm{CO}_{2}$ emissions by the WEO 450 as defined in WEO 2015. The carbon emissions after the year 2040 are extrapolations from pre-2040 values implying that no great disturbances will occur. Intermediate curve shows the reduction of $\mathrm{CO}_{2}$ emissions for the strategy of elimination of coal power plants in the years 2025-2065. Replacement emission reduction would grow linearly from zero in 2025 to $11.8 \mathrm{Gt}$ of $\mathrm{CO}_{2}$ by the year 2065. The figure of 1,600 $\mathrm{GW}$ of nuclear power to replace annual production of 12,304 TWh of coal power electricity does not take into account possible contribution by coal power plants equipped with CCS systems. Should these systems be developed in time, nuclear replacement power could be appropriately reduced in future years, 1,600 GW would be the upper limit for nuclear replacement. However, prospects of CPP with CCS to replace CPP without CCS are very limited, thus we would not expect significant reduction of nuclear build up. Effects on carbon emission by the replacement of 1,600 GW of coal power plants in the years 2025-2065 are even more remarkable if expressed over reactors operation time. For linear growths of replacement power from zero to $1,600 \mathrm{GW}$ emission reduction would amount to $236 \mathrm{Gt}$ of $\mathrm{CO}_{2}$ for the period 2025-2065. Should nuclear power plants continue operating after 2065, as the economy would require, until the end of 40 years working life of all nuclear plants by 2105 , we would double the emission saving to $472 \mathrm{Gt}$ of $\mathrm{CO}_{2}$, without adding to the basic investment. With longer operating life of nuclear power plants exiting by 2125 emission savings would be larger by additional $236 \mathrm{Gt}$, approaching a total of $708 \mathrm{Gt}$. 


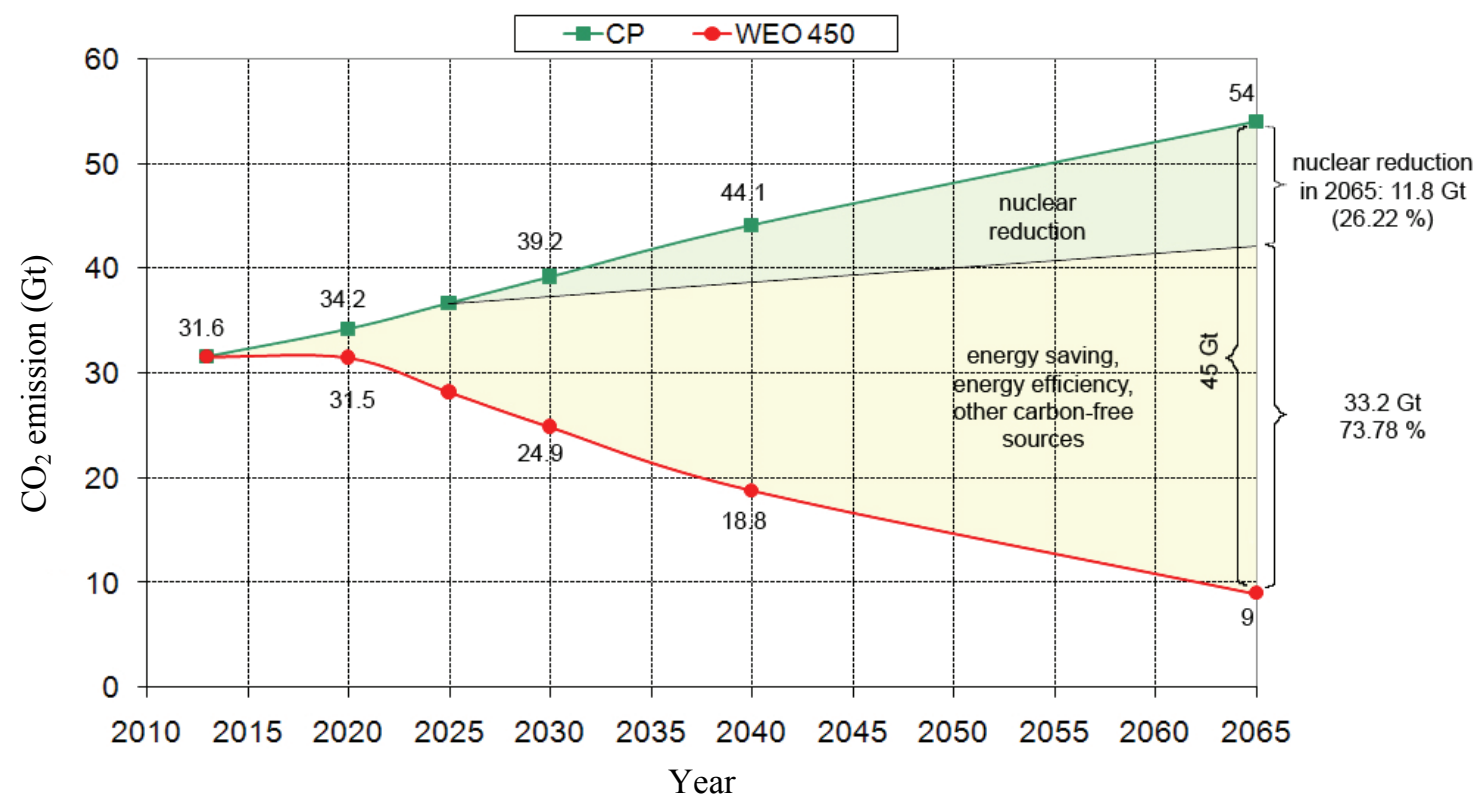

Fig. $2 \mathrm{CO}_{2}$ emissions for WEO 2015 current policy energy strategy, WEO 450 energy strategy, and for proposed energy strategy in $\mathrm{Gt}_{\mathrm{CO}}$ for the period 2013-2065.

A very preliminary CPP replacement cost estimates indicate that increasing carbon emission tax could have significant effect in offsetting larger investment costs of nuclear power plants. Expected international legislation is likely to result in an essential increase of carbon tax, in parallel with the growing public awareness of global warming effects. Various agencies give a spectrum of forecasts, all expecting large increase of carbon tax [13, 14]. Assuming the carbon tax for years after 2025-2105 in the range of $\$ 50 /\left(\mathrm{tCO}_{2}\right)$ to $\$ 150 /\left(\mathrm{tCO}_{2}\right)$, charge on the emission of $472 \mathrm{Gt}$ of $\mathrm{CO}_{2}$ during $40+40$ years of nuclear power plants operation would amount to $23,600-70,800$ billions of USD. Should the LWR replacement plants be of one GW each, the saved carbon tax per one reactor would come between 14.8 and 44.3 billion dollars. Depending on applicable future value of carbon tax, in a time much shorter compared with reactor operation, from about ten to twenty years, carbon tax saving could cover the cost of nuclear replacement. For extended nuclear reactor lifetimes carbon savings per reactor unit would rise correspondingly. Furthermore, the nuclear power plants built in large numbers of many hundreds units, of standardized design and serial production, would offer very substantial investment reduction.

\section{A Comment on Advanced LWR Reactors Operations after 2065}

In our preceding research [7] we only briefly discussed possible ways to continue nuclear fission energy production after 2065. We give here few comments on the question how to continue with sustainable fission energy after 2065. Looking at the proposed strategy for NPPs with their working life of 40 years after the year 2065, the operation of advanced LWR reactors $(2,100 \mathrm{GW}$ of nuclear capacity) would be terminated (without extension) as required by economy in 40 years with the last reactor working up to the year 2105. The uranium requirements for operating these reactors in the period 2065-2105 would amount to $6.13 \mathrm{Mt}$ of uranium. With consumption during years up to 2065 amounting to $8.94 \mathrm{Mt}$ we are very close to $15 \mathrm{Mt}$ of uranium requirements for this strategy up to 2105 . For longer working life of LWR of 60 years situation would be a little bit different. First reactors started to operate in 2025 would retire by 2085 and the last one built in the 
period 2025-2065 would operate until 2125. The older reactors built before 2025 (assumed working life of 40 years) are replaced by advanced LWR with working life of 60 years. Therefore, all reactors built after 2025 would operate until 2085. After 20 years of operation on the level of $2,100 \mathrm{GW}$, from 2065 to 2085 , the nuclear power would linearly decrease to zero in 40 years, finishing at zero power by the year 2125 . Total uranium consumption for that strategy would amount to $22 \mathrm{Mt}$. Both the figures of $15 \mathrm{Mt}$ and $22 \mathrm{Mt}$ required in the next century seem to be acceptable on the basis of our uranium reserves estimates in Ref. [9]. A decision on 40 years or 60 years of operation life would come from other considerations. Both these options would have advantage in extending the production of nuclear energy for several decades without the necessity to change the nuclear technology. Should recycling of plutonium be applied after 2065 it would reduce the uranium requirement, but at the cost of losing the choice of long term strategies requiring plutonium as starting charges. Should the need for nuclear fission energy on the large scale continue after the year 2065 and into the next century we have options of practically unlimited production of fission energy by introducing new nuclear technologies that use nuclear breeding principles. In that case a reprocessing of nuclear fuel becomes unavoidable.

\section{Summary and Conclusions}

On the basis of our earlier study, evaluating the potential of nuclear energy to contribute essentially to mitigation of climate problems, with new data and consideration of new developments we presented nuclear strategy defined by environmentally attractive and technically less challenging target of replacing all non CCS coal power plants in the years 2025-2065, after the expiration of their working life, with nuclear power plants. These replacements would remove worst emitters of carbon producing annually 12,304 TWh of electricity (WEO 2015). Required replacement nuclear power would amount to 1,600
GW. Reduction of carbon emission through this replacement would by 2065 reach $26.22 \%$ relative to the total reduction of $45 \mathrm{Gt} \mathrm{CO}_{2}$ required to bring in the year 2065 the WEO Current Policy energy strategy down to the WEO 450 energy strategy limiting the global temperature increase to $2{ }^{\circ} \mathrm{C}$. The emission saving by replacing CPPs would be $21.9 \%$ in the year 2065 when it is compared with carbon emissions in the year 2065 according to the current policy strategy as defined by WEO 2015. Rational investment use would demand that reactors built in the 2025-2065 period be retired after full working life of 40 years, in the transition period of 40 years until 2105. By that time $\mathrm{CO}_{2}$ emission reduction would reach $472 \mathrm{Gt}$, or even considerably more, to $708 \mathrm{Gt}$ should the working life of nuclear power plants be extended to 60 years. Preliminary attempt was made to point out some interesting financial aspects of the replacement of CPP. Depending on likely future evolution and legal status of carbon tax a strong inducement to replace CPP may well arise. In CPP replacement strategy total uranium consumption without reprocessing, including transition period 2065-2105 would reach $15 \mathrm{Mt}$ for the lifetime of nuclear power plant of 40 years. For the lifetime extension to 60 years applied to replacement plants $(1,600 \mathrm{GW})$ and not to older plants built before 2025 , total uranium consumption would by 2125 reach $22 \mathrm{Mt}$

After recent years of rising awareness of the reality and the threat of global warming in parallel with fading promise of nuclear fusion and CCS, informed energy community should be more inclined to accept nuclear contribution to climate change mitigation, at least for the climate critical years up to 2065. Nuclear fission has the additional value of supporting intermittent sources by covering a base load consumption. The replacement of coal power plants with nuclear power plants in the period 2025-2065, may well turn to be a good long term economic policy expecting the probable large increase of carbon taxes. After the Paris climate conference recognising the 
urgency of measures to mitigate climate changes removal of coal as the worst climate offender would be a significant step towards the climate control.

\section{References}

[1] Pachauri, R. K., and Meyer, L. A. 2014. Contribution of Working Groups I, II and III to the Fifth Assessment Report of the Intergovernmental Panel on Climate Change. Intergovernmental Panel on Climate Change (IPCC): Climate Change 2014: Synthesis report, Geneva, Switzerland.

[2] Meinshausen, M., Meinshausen, N., Hare, W., Raper, S. C. B., Frieler, K., Knuitti, R., Frame, D. J., and Allen, M. R. 2009. "Greenhouse Gas Emission Targets for Limiting Global Warming to $2{ }^{\circ} \mathrm{C}$." Nature 458 (April): 1158-62.

[3] Friedlingstein, P. 2015. "Carbon Cycle Feedbacks and Future Climate Change". Philosophical Transactions of the Royal Society of London A: Mathematical, Physical and Engineering Sciences 373 (2054): 20140421.

[4] Koningstein, R., and Fork, D. 2014. "Today's Renewable Energy Technologies Won't Save Us. So What will?" Spectrum, IEEE-International, 31-5.

[5] IEA (International Energy Agency). 2009. World Energy Outlook 2009. OECD/IEA report.

[6] Biello, D. 2016. "Carbon Capture May Be Too Expensive to Combat Climate Change." Scientific American 314 (1): 59-65.

[7] Knapp, V., Pevec, D., and Matijevic, M. 2010. "The Potential of Fission Nuclear Power in Resolving Global Climate Change under the Constraints of Nuclear Fuel Resources and Once-through Fuel Cycles." Energy Policy 38 (11): 6793-803.

[8] OECD/NEA-IAEA. 2008. Uranium 2007: Resources, Production and Demand. Organization for Economic Co-operation and Development/Nuclear Energy Agency-International Atomic Energy Agency.

[9] Pevec, D., Knapp, V., and Trontl, K. 2012. "Long Term Sustainability of Nuclear Fuel Resources." In Advances in Nuclear Fuel. Rijeka: InTech.

[10] World Nuclear Association Information Library. 2016. World Nuclear Power Reactors \& Uranium Requirements.

[11] IEA (International Energy Agency). 2015. Energy and Climate Change. OECD/IEA report.

[12] IEA (International Energy Agency). 2015. World Energy Outlook 2015. OECD/IEA report.

[13] Luckow, P., Stanton, E. A., Fields, S., Biewald, B., Jackson, S., Fisher, J., and Wilson, R. 2015. 2015 Carbon Dioxide Price Forecast. Synapse Energy Economics report.

[14] Climate and Carbon-Aligning Prices and Policies. 2013. OECD Environment Policy paper. 